\title{
The priority classification method of mobile users under direct power transaction
}

\author{
Wang Lei ${ }^{1,2}$, Gao Chuncheng ${ }^{1,2}$, Zhang Qian ${ }^{1,2, a}$ and Dai Yong ${ }^{1,2}$ \\ ${ }^{1}$ Nari Group Corporation/State Grid Electric Power Research Institute Nanjing China \\ ${ }^{2}$ Beijing Kedong Electric Power Control System Co., Ltd. Beijing China
}

\begin{abstract}
With the development of mobile internet technology, market-oriented electricity reform forms a new transaction mode that "Internet + power trading", which further promotes the liberalization of retail side market. A large number of mobile power users actively participate in the electricity market transaction. However, the current standards for mobile users who are accessed to the market are qualitative standards, lacking of quantitative analysis. The priority classification method of mobile users under direct power transaction is proposed in the paper. First, the priority evaluation index set of mobile users is established from four dimensions that credit condition, environmental condition, power consumption condition and load importance to achieve evaluation quantitatively. Secondly, Kmeans clustering algorithm based on SOM is used to cluster mobile users. Finally, the paper recognizes the various types of mobile users as a whole and estimates their priorities using the improved AHP(Analytic Hierarchy Process). The method realizes the specific division of mobile users from a point of quantitative view, and solves the problem of only qualitative standard currently, to optimize the development of direct power transaction and promote the marketization of power market.
\end{abstract}

\section{Introductuion}

The direct power transaction is that power plants and power users determine the purchase of electricity and electricity prices through the form of direct power transactions, and then commission power grid companies to transfer the power of the agreement from the power generation enterprises to the power users and pay for the transmission and distribution services undertaken by the grid companies.

Meanwhile, with the continuous deepening of the mobile direct power transaction, a large number of mobile power users actively participate in the direct power transaction. The domestic and foreign electricity market has defined the conditions for the transfer of members of the direct electricity market. All electricity users in the US electricity market can trade directly online, but large users need to pay for grid service fees to power grid companies. The European electricity market is open to users whose electricity consumption is more than 9 million $\mathrm{kWh}$. At present, large domestic direct purchase of electricity to emphasize too much access to large users of electricity scale, although it is clearly stipulated in the transaction implementation in various regions that large users involved in direct power transactions should conform to the national industrial policies with low energy consumption per unit output in the same industry and small pollution emission.

\footnotetext{
${ }^{a}$ Corresponding author: E-mail:hbkjdx2009@126.com
}

However, the admittance standards are all qualitative, and in practice it will involve how to make a concrete division. In order to realize the quantitative evaluation of the priority [5-6] of the mobile terminal users, this paper proposes a priority evaluation index system [7-8], evaluates its priority by using improved AHP [9-10], which achieves the quantitative division of mobile users.

\section{The comprehensive evaluation model of supervision risk in electricity transaction based on unascertained rational number}

The mobile user priority evaluation indicator system includes four first-level indicators which are credit condition, environmental condition, power consumption condition and load importance, and 11 second-level indicators, as shown in the following figure. 


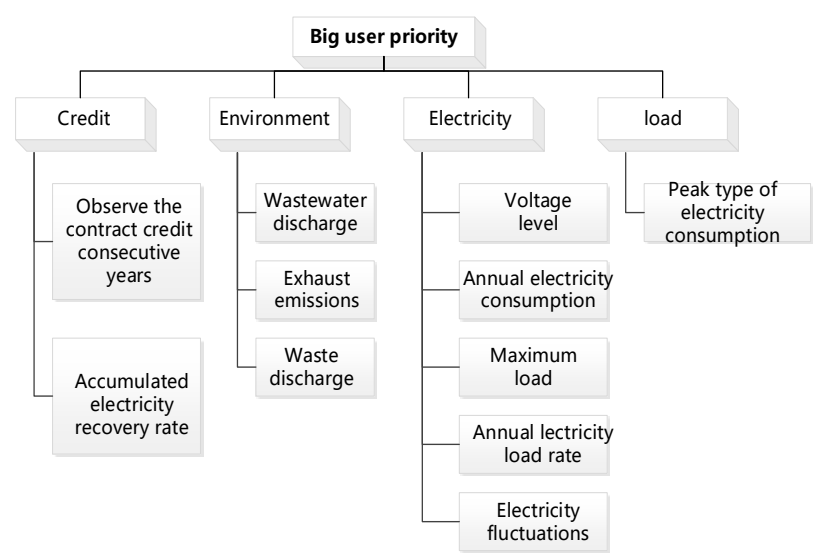

Figure 1. evaluation indicator system

(1) Credit condition (S1)

Accumulated electricity recovery rate $(\mathrm{S} 12)$ is as follow. Refer to “(1),"

$$
\mathrm{S} 12=\frac{a}{b}
$$

In the formula:

a: a user's received electricity bill over the past three years.

b: a user's receivable electricity bill over the past three years.

(2)Environmental condition (S2)

Environmental condition (S2) is as follow. Refer to “(2),"

$$
\mathrm{S} 2=\frac{1}{2} \sum_{i=1}^{3} S 2 i
$$

The expression of each sub-indicator is as follow. Refer to “(3),"

$$
\text { S2i }=\left\{\begin{array}{c}
0 \\
\left(S_{i}-S_{i}^{-}\right) /\left(S_{i}^{+}-S_{i}\right) \\
1
\end{array}\right.
$$

In the formula:

Si: the i-th pollutant emissions, $i=1,2,3$.

$S_{i}^{+}$and $S_{i}^{-}$respectively represent the upper and lower limits of such pollutant discharge stipulated by our country.

(3) Electricity condition (S3)

The users' voltage class is generally divided into five categories, that is, less than $1 \mathrm{KV}, 1-10 \mathrm{KV}, 35-110 \mathrm{KV}$, $110 \mathrm{KV}$, and $220 \mathrm{KV}$ and above. Accordingly, the quantized values of the user's voltage level (S31) are respectively recorded as $1,2,3,4$, and 5 .

Annual electric load rate (S34) is expressed as follow. Refer to "(4),"

$$
\mathrm{S} 34=\frac{10000 * S 32}{8760 * S 33}
$$

Electricity fluctuations (S35)is expressed as follow. Refer to “(5)-(6),"

$$
\mathrm{S} 35=\frac{\sqrt{\frac{1}{12-1} \sum_{i=1}^{12}\left(L_{i}-L\right)^{2}}}{L}
$$

$$
\mathrm{L}=\frac{1}{12} \sum_{i=1}^{12} L_{i}
$$

In the formula:

$\mathrm{L}$ (ten thousand $\mathrm{kWh}$ ): the average of the monthly electricity consumption.

$\mathrm{Li}$ (ten thousand $\mathrm{kWh}$ ): the electricity consumption of the big user in the I-th month. S5 is the standard deviation of the large user's monthly electricity consumption divided by the average monthly electricity consumption, which indicates the fluctuation and periodicity of the user's monthly electricity consumption.

(4)Load condition (S4)

Peak-class enterprises have excellent power consumption insurance category, A class, B class, C class and limited class. Accordingly, Peak type of electricity consumption (S41) are respectively recorded as 5, 4, 3, 2 and 1 .

\section{Clustering Analysis of Mobile Terminal Users Based on Improved K-means Clustering Algorithm}

K-means clustering algorithm based on SOM belongs to two-stage calculation method. In the first stage of the initial clustering, SOM first cluster massive data samples and classify the eigenvectors with similar characteristics to the same category, so that the sample data can be clustered into different categories, and the number of categories and the central point of each category can be obtained. In the second stage, the K-means clustering uses the result of the first stage as the initial value input and further clusters to form the final clustering result.

\section{The Priority Evaluation of Mobile Terminal Users Based on Improved AHP Algorithm}

(1) The improved AHP algorithm

The traditional AHP usually uses the I-9 scale method to establish the judgment matrix. If it is not consistent when tested, the matrix will affect the effect of AHP's optimal sorting, and it must be reconstructed until it passes the test, so the computation is large and the accuracy is not high.

The improved AHP adopts a new scale method - the three-scale method, which does not need consistency test when judging and comparing the relative importance of the factors to each other. Therefore, the number of iterations can be greatly reduced, the convergence speed can be improved and the calculation accuracy can be met. The comparison matrix constructed by the three standard method is expressed as follow. Refer to "(7),"

$a_{i j}=\left\{\begin{array}{l}2: \text { Index } i \text { ismore important thanindex } j \\ 1: \text { Index } i \text { is as important as the index } j \\ 0: \text { Index } i \text { less important than index } j\end{array}\right.$

In the formula,

$a_{i j}$ : the element value of the matrix $A$ 
Besides, calculate the importance ranking index $r_{i}$ of each index. Construct the judgment matrix $\mathrm{B}$ and find the quasi-optimal consistent matrix D.

(2) Mobile terminal user priority evaluation

TOPSIS does not reflect the subjective preference in the evaluation. In this paper, TOPSIS is used to determine the final solution.

Calculate the approximate degree $\mathrm{T}_{\mathrm{i}}$ of each sample and the virtual result. Refer to " $(8)$, ,

$$
T_{i}=d_{i}^{-} /\left(d_{i}^{+}+d_{i}^{-}\right)
$$

$\mathrm{T}_{\mathrm{i}}$ is between 0 and 1 . The samples are sorted according to $T_{i}$, that is, the greater the $T_{i}$ shows, the closer the solution represented by the result is to the optimal solution and the farther it is from the worst solution.

\section{Conclusion}

In this paper, the priority classification method of mobile users under direct power transaction is proposed. The method selects evaluation indexes and establishes the mobile user priority evaluation indicator system, which includes four aspects, being credit condition, environmental condition, power consumption condition and load importance, and quantifies the priority of mobile users from multiple indicators, solving the problem of now only qualitative criteria, and laying a research foundation for mobile terminal user priority classification.

\section{References}

[1] Qi-ping FENG. "Research on Electricity Transmission-Distribution Independent and Large Consumers Direct Purchasing Based on Power Market," Central South University, 2014.

[2] Liang TAO. "Research on the Direct Power Purchase for the Large Customer," Beijing: North China Electric Power University, 2014.

[3] Fu-bin LIU, Tao PENG, Xian ZHANG, Bo PANG, Ye HAN. "Pilot and Promotion Recommendations for Direct Trading between Power Users and Plants," East China Electric Power, vol.41, no.9, pp.1941-1944, 2013.

[4] Wei CHEN, Jing-jing YANG. “'Palm Power' bloom capital," State Grid, no.9, pp.86-87, 2015.

[5] Qi-zong SUN, Jia-ji ZHONG, Chuan CHEN, Ertian HUA. "Method of determining customized priority based on customer preferences," Journal of Mechanical \& Electrical Engineering, vol.34, no.11, pp.1354-1358, 2017.

[6] Li-qiong JIANG. "Research on Access Technologies of Dynamic Users in Space-based Network on Account of Traffic Priority," Harbin Institute of Technology, 2017.

[7] Yang-sen OU, Li-yuan LIU. "Reliability Index System of Distribution Network for Power Consumer and Its Comprehensive Assessment Method Power," System Technology, vol.41, no.1, pp.215-222, 2017.

[8] OU Yangsen, Shi Yili. "A new improved entropy method and its application in power quality evaluation," Automation of Electric Power Systems, vol.37, no. 21, pp.156-159+164, 2013.
[9] Tong LIU, Mu HE, Yu-xiao WANG, Qing-yu YAN. "Comprehensive Evaluation on the Satisfaction for Water Park in Tianjin with the AHP and Kano Model," Journal of Shandong Agricultural University (Natural Science Edition), vol.47, no.3, pp.417-424, 2016.

[10] Yao-tian ZHANG, Xu-cheng ZHANG, Ming-shun JIA, Xiang-shang XUE. "Adaptive evaluation method based on analytic hierarchy process," Journal of Beijing University of Aeronautics and Astronautics, vol.42, no.5, pp.1065-1070, 2016.

\section{Acknowledgment}

This work was funded by the headquarters technology project of state grid corporation of China "Research on the operation risk analysis and support technology of electricity market in the interaction of supply and demand". 